This is an Accepted Manuscript of an article published in International Journal of Educational Development, available online at http://www.sciencedirect.com/science/article/pii/S073805931500022X

Published details:

Renu Singh and Sudipa Sarkar (2015) 'Does teaching quality matter? Students Learning Outcome Related to Teaching Quality in Public and Private Primary Schools in India', International Journal of Educational Development 41: 153-163, Doi:10.1016/j.ijedudev.2015.02.009

\title{
Does teaching quality matter? Students Learning Outcome Related to Teaching Quality in Public and Private Primary Schools in India.
}

\section{Introduction}

India launched its flagship programme Sarva Shiksha Abhiyan in 2001, to meet MDG 2 Goal of Universalisation of Elementary Education (Grade 1-VIII). As a result, the recent years have witnessed a huge increase in enrolments in both public as well as private schools across the country. There is indisputably a growing shift towards private schooling, not only in urban areas, but also across rural India, where low fee charging private schools have mushroomed, carrying the fashionable tag of 'English medium'. Studies such as the Seventh Annual Survey of Education, show an increase in national level private school elementary school enrolment ( age group 6 to 14 years) from 18.7 per cent in 2006 to 25.6 in 2011, except in Bihar which has the unique distinction of actually decreasing the proportion enrolled in private schools because of opening of a large number of Public schools and recruitment of teachers (ASER 2011). National statistics reveal that 187,872,996 students are enrolled in elementary classes in India out of which 69.5 percent of the students are enrolled in Public or government schools and close to 34 percent of elementary students ( Grades I-VIII) attend 19.4 percent of schools that are either private aided or unaided (DISE 2009-10). Indian schools are broadly categorized into three categories: (1) public schools run by various state education departments i.e. government owned and controlled which do not charge fees(2) Private aided schools i.e. schools managed by private bodies but receiving funds from the government to pay salaries of teachers, which in general charge fees much lower than private unaided schools and lastly(3) private unaided schools which are privately managed, do not get any aid from the government and survive by charging fees from the students. Private unaided schools frame their own admission rules and fee structure for students and tuition fee may vary from Rs. 30 to Rs. 4000 per month depending on the location and services provided by the school. It is critical to mention at the outset that 
private schools are not homogeneous in nature and that is why one can find, very low fee charging schools in rural and urban slums of India and internationally competitive high fee charging elite private schools in urban areas, catering to rich students. This paper is limited to investigating low fee charging unaided private schools, catering to children belonging to economically weaker families.

The enactment of the Right to Free and Compulsory Education Act, 2009 ratified in April 2010 (RtE Act) has made it a constitutional obligation for all 35 states and Union Territories in India to provide students between the ages of 6-14 access to free and compulsory education in a neighbourhood school till completion of elementary education (Article 3). At the time the Act was notified, it was estimated that the total number of additional teachers required to meet the prescribed pupil teacher ratio under the Act in public schools, was approximately 1.2 million teachers, in addition to ensuring that 0.5 million currently employed unqualified teachers get the requisite qualifications within three years.

Even after the enactment of RtE Act, percentage of single teacher primary schools remains at 12.26 percent with states like Arunachal Pradesh having 65.12 percent single teacher primary schools. This is further exacerberated by teacher absenteeism and lack of accountability (Ramachandran et al, 2005). A range of quantitative and qualitative studies done in the past two decades (PROBE 1999, Ramachandran, et al 2004, De, et al 2001, Majumdar 2001) reveal a distressing picture of the learning achievements of students. The Seventh Annual Survey of Education Report (ASER, 2011) has also shown an alarming decline in mathematics skills in rural schools, with the number of class III students able to solve subtraction problems falling from 36.6 per cent in 2010 to 29.9 per cent in 2011.

\subsection{Teaching Quality}

EFA and MDG 2 cannot be realised unless needs of all learners are met and this is highly dependent on teaching quality. Teaching and teacher quality have innumerable definitions and are sometimes linked together or used in isolation. This paper considers teaching quality to be an amalgamation of both teacher characteristics such as inputs (professional qualifications, experience, place of residence, in service training etc) as well as what the teachers 'does' and demonstrates in the classroom (practices, attitudes and content knowledge). This has been aptly elaborated by Fenstermacher and Richardson (2005):

Quality teaching can be understood as teaching that produces learning. In other words, there can indeed be a task sense of teaching, but any assertions that such teaching is quality teaching, depends on student learning .... we label this sense of teaching successful teaching (p.186)

Darling-Hammond (2000), stresses that teacher quality is one of the most important factors contributing to student achievement, more significant than class size. Of all the variables associated with effective schools, the quality of teaching, has both the most consistently demonstrated impact on student learning and is within the power of schools to do something about (Wyatt, 1996). The McKinsey report (Barber and Mourshed, 2007) which studied 25 school systems, identified teacher quality as being crucial to high quality education. While 
many studies have undertaken a comparison of private and public schools in India and proclaimed the cost effectiveness of private schools (Kingdon, 1996a, Tooley et al 2007 ) and also higher test scores((PROBE 1999, Ramachandran, et al 2002 and 2004, Muralidharan and Kremer,2006 ), not many studies have focussed on quality of teaching within these schools and the effect on learning outcomes across private and public schools. Fuller and Clarke (1994) assert that there is a lack of evidence in developing countries that investigate teaching behaviours and classroom factors that promote favourable student outcomes.

The assumption that quality teaching leads to better student outcomes is an assumption that this paper adopts, since teaching is as seen as facilitating learning. This paper examines how teaching and teacher quality in public and low fee charging private schools measured by a variety of factors ranging from teacher characteristics such as maths content knowledge of teachers and teacher professional qualifications, instructional dimensions such as multi-grade teaching, regular feedback by checking books and teachers proximity to the school, as well as larger organisational dimensions such as teacher accountability, are related to student outcomes. Student outcome is measured by maths achievement level of students in the schools. The paper makes a critique of systemic issues related to the public education system, which is increasingly being abandoned by even the poorest of families who are taking on debts to pay for private education for their students, since they are convinced that their sacrifices would result in a 'better future; for their children.' Section 2 provides details of Young Lives survey and sample for the school-based study, Section 3 focusses on methodology, Section 4 covers the analysis and results, while Section 5 and Section 6 highlight the recommendations and conclusions respectively.

\section{Young Lives}

This paper draws on the India sample of the Young Lives longitudinal study, which is from the state of Andhra Pradesh ${ }^{1}$. Andhra Pradesh (AP) is the 5th largest state in India, with a population of over 80 million, 73 percent of who live in rural areas. Andhra Pradesh which ranks 14 out of 35 states in India on the Composite Educational Index (DISE 2010), has also been impacted by the phenomenon of increasing private school enrolments, similar to National trends illustrated earlier. According to DISE 2010 (NUEPA, 2011), Andhra Pradesh had a total of 102, 798 schools imparting elementary education of which 77.6 percent (79, 813 schools) were Public schools (comprising local body, tribal welfare and department of education schools) and 22 percent (22, 985 schools) were private schools. According to ASER 2010, between 2009 and 2010, the percentage of students (age 6-14) enrolled in private school has increased from 29.7 percent to 36.1 percent in Andhra Pradesh. Policy planners are faced with a situation where even the poorest of families are opting for low-fee 'English-medium' private schools, which are often run by entrepreneurs such as young graduates or someone with rooms to spare within their own homes, both in rural areas as well as urban slums.

So far, data on the Young Lives students, households and communities have been collected in three rounds- 2002, 2006-07 and 2009-10 respectively. The Round 3 Young Lives India Survey

\footnotetext{
${ }^{1}$ The state of Andhra Pradesh has been bifurcated into the two new states of Telangana and Andhra Pradesh on June2nd, 2014
} 
Report (Galab et al. 2011) highlighted that there was a significant increase in enrolment of Young Lives students in private schools at the age of 8 between 2002 and 2009. 44 per cent the Younger Cohort aged 8 in 2009, were enrolled in private schools, compared to only 23 per cent of the Older Cohort when they were 8 in 2002. The report shows that private school enrolment has gone up for every group - male, female, rural, urban and all the different official caste and tribal groupings, ${ }^{2}$ and that private school enrolment has approximately doubled in 2009, compared to 2002. However, serious equity concerns exist, with increased enrolment far from evenly distributed and gender-based school choices more prevalent (Woodhead et al. 2011). In 2009 (Round 3 survey), the parents of eight year old children were asked about the main reason for choosing a particular school for their child. It is interesting to notice that while 53 percent of parents who sent their children to public schools, cited close proximity to school as the main reason for choosing the school, only a miniscule 6 per cent said cited good-quality teaching. On the contrary, amongst the parents who sent their children to private schools, 63 per cent refer to the good-quality teaching and 22 per cent chose the private school due to proximity to their home (Singh \& Sarkar, 2012).

A number of studies in India have focussed on studying private and public schools in various states of India. Kingdon (1996a) challenged the prevailing notion in Indian writings, based on official published data, that the size of the private sector in primary education was "infinitesimally small" or "negligibly small." A study conducted in Hyderabad, Andhra Pradesh found 65 percent of school children attending private unaided schools in 'slum' areas of three zones of the Old City of Hyderabad (Tooley, Dixon \& Gomathi, 2007). In terms of learning achievements, children attending private unaided schools in Madhya Pradesh outperformed children attending government schools in maths and Hindi, with 'managementtype - government or private' emerging as the most significant factor influencing learner achievement' (Govinda and Varghese, 1993, p. 265). Kingdon (1996 b) in a study in urban Lucknow, Uttar Pradesh, found that, after controlling for background variables, students in private unaided schools scored higher on standardised tests in mathematics than in the other school types. When the cost per achievement point was computed, private unaided schools achieved higher achievement for less than half the cost of the government schools. Muralidharan and Kremer (2006) in their national survey of 20 states of India, found that private schooling was utilized by the poor in India. They also highlighted that children in private schools have higher attendance rates and superior test score performance, with the latter being true even after controlling for family and school characteristics.

While there is clear evidence that quality teaching is a key determinant of student learning, little is known about which specific observable characteristics of teachers can account for this impact (e.g., Rockoff 2004; Rivkin, et al 2005). This paper examines how teaching and teacher quality in public and private schools are related to student outcomes in mathematics. The latter is measured by the level of maths achievement of children in the schools. The research question that guides the paper is whether teaching quality has impacted mathematics

\footnotetext{
${ }^{2}$ Scheduled Castes, Scheduled Tribes, Backward Classes and Other Tribes are official designations made by the Public of India. Disadvantaged groups are given legal protection and other benefits designed to compensate for the discrimination they have suffered for centuries.
} 
achievement scores of students in primary schools, and whether the effects are different in private schools as compared to public schools. Factors that impinge teaching quality such as teacher qualifications (educational degrees, professional qualifications, experience), teacher characteristics (subject knowledge, teacher motivation, teacher's perception about schools, absenteeism and distance of residence from the school, teaching practices e.g. checking of books along with system related factors such as salaries and multi-grade classrooms are analysed for their effect on learning outcomes.

\subsection{Data}

This paper draws on data from the Young Lives study in India, conducted in the state of Andhra Pradesh. So far, data on the Young Lives students, households and communities have been collected in three rounds of survey conducted in 2002, 2006 and 2009. The survey is complemented by in-depth qualitative research with a sub-sample of 50 children in four communities. Since the Young Lives survey rounds did not investigate schools that the Index children were attending, in 2010-11, a school-based study was conducted on a subset of schools where Younger Cohort aged 9 years were studying. While the child- and household-level data is longitudinal in nature, consisting of three time periods, the school survey data is crosssectional. However, we have the advantage of also being able to use child- and household-level data from other survey rounds. In this way, while we mainly look at educational indicators from the school survey, we can control for background characteristics of the students and their families by using the longitudinal data. This paper also draws on qualitative sub-study which accompanied the school-based study and was undertaken in 2011, in which factors that shape choice of schools was explored by interviewing 30 children and their caregivers. The design for the School Study qualitative research adapted methods used in Young Lives qualitative research including 'school history' draw-and-tell method for use with children. Semi-structured interviews explored parents' perceptions, expectations and aspirations for their children, and the processes underlying their choice of school. Thus both qualitative and quantitative information informs this paper. In the following sub-section we briefly illustrate the sampling procedure which was followed for the school survey.

\subsection{Sampling}

The school-based study was conducted on a sub-sample of 953 younger cohort children aged 9 years, studying in 249 schools in Andhra Pradesh in 2010-11, located across nine districts of Andhra Pradesh. Stratified sampling was utilised to ensure representation of rural, urban, public and private aided and unaided schools. Schools had an average of four Young Lives children studying in them. Eight tools were employed for the school-based study. These included child questionnaires to garner information about student's perceptions of school and teaching quality, including teacher absenteeism and teacher behaviour in the classroom. Head teachers were interviewed to provide further data on teacher qualifications, pupil-teacher ratios, teacher dismissal, parental involvement, etc. The school-based study also collected data on teachers employed in these schools. In particularly, information was sought from teachers who taught 
maths to the Young Lives students, using a separate questionnaire. Many of these teachers were not subject teachers alone, and were often the class teacher or even the head teacher. Since the diagnosis of a student's errors in mathematics is a fundamental skill for teaching the subject, a test was devised for teacher's responses to students' mathematical errors, in order to examine teachers' subject knowledge. School observations gathered information regarding school physical infrastructure and facilities while classroom observations were used to collect information on classroom processes and teaching and learning methodologies adopted in the classroom. The school-based study also captured insights of 33 education officials (District Education Officers and Mandal Education Officers) about community and their own perceptions of private and public schools, governance and quality issues, particularly within public schools.

Besides, this child tests were conducted for language and mathematics. For this paper, we have analysed scores attained in the mathematics achievement test alone. The mathematics achievement test consists of two sections. The first section is aimed at measuring basic quantitative and number concepts. It included seven items on number identification, seriation and simple problem sums, with no time limit. The second section consists of 14 items which include two-digit and three-digit addition, subtraction, multiplication and division with a time limit of six minutes.

For the purpose of this paper we only take into consideration public (government) and recognised private unaided schools. Our final sample consists of 227 schools, 357 teachers and 862 Young Lives children in public and private unaided recognised schools in both urban and rural areas $(\text { Table } 1)^{3}$.

\section{Methodology}

To examine the effect of teaching in public and private schools on students' learning outcomes, we begin with descriptive statistics of teaching quality found in the private and public schools. Teaching quality is measured by examining teacher characteristics from the Teacher and Child Questionnaires, and teaching practices. We also acknowledge the fact that there can be several confounding factors such as socio-economic and other background characteristics coming into play and affecting student's learning outcomes. To separate out these partial effects and identify the effect of each of these factors, we carry out a multivariate regression analysis. We estimate four separate regression equations. The first one is the Ordinary Least Square (OLS) estimation and the second one has a similar specification to the first, but in addition it has a variable to capture lagged test scores of the students. In this sense, it is dynamic in nature. The reason for including the maths test score from the Round 3 survey (2009) is that it reflects student's ability to perform in a similar test. Therefore, in this second specification, which is a lagged value-added specification, we control for the student's ability to a large extent, in order to yield consistent estimates for the other variables which may be correlated with ability. We also control for mandal (sub-district) level heterogeneity in value-added specification in our

\footnotetext{
${ }^{3}$ Regression results are based on non-missing values of all the variables included in the model. Only few observations have been dropped for missing values which do not affect descriptive statistics much. So we present the descriptive statistics based on full sample.
} 
third regression and allow mathematics teacher and teaching quality specific variables for heterogeneity in the effect size in private and public schools in the last regression

\section{Analysis and results}

In this section, we analyse Young Lives school-based study data to investigate how teaching quality affects students' learning outcomes and whether this effect varies across public and private schools. We focus on mathematics teachers and associated teaching quality pertaining to them alone.

\subsection{Comparison of learning outcomes between students in public and private schools}

Learning outcomes for students in public and private schools were measured by mathematics test scores. Scores for the 21 items on the test have been generated using Rasch model scaled from 0 to 100. The advantage of generating Rasch score, is that it takes into account the difficulty level of each item and corrects for possible bias ${ }^{4}$.

Table 1 captures descriptive analysis of student outcomes and various teacher characteristics and practices within public and private schools. The table reveals that students in private schools have 6.7 percentage point higher average score in mathematics than students in public schools. A t-test to compare the mean test scores confirms that this difference is statistically significant at 1 per cent level. The above comparison between the mean test scores, strongly suggests that students going to private schools have a significantly higher learning outcome in mathematics than students who go to public schools. However, with a view to analyse and evaluate their performance in a more elaborate way, we compare the distribution of test scores between students attending public and private schools. Figure 1 juxtaposes the two kernel density functions of maths scores in private and public schools. We notice that not only the mean, but the whole distribution of test scores in private schools is to the right-hand side of the distribution pertaining to public schools. Thus, there is strong evidence from the data that students in private schools are achieving better results, at least in terms of mathematics, than the students in public schools. This difference in performance could be due to quality of school inputs as well as different intakes in public and private schools. We therefore try to investigate if these test scores are affected by teaching quality.

To begin with we analyse mathematics teacher characteristics and examine how they differ across public and private schools. We also conduct a t-test to test whether the differences are statistically significant. In public schools teachers who taught mathematics, comprised of head teachers, regular teachers and contract teachers called Vidya Volunteers. In private schools 80 percent of the mathematics teachers were employed on contractual basis. Private school teachers are mostly employed on temporary basis and are paid four times less than public school teachers ${ }^{5}$. There are more than twice as many female mathematics teachers in private schools as in public schools. Teachers of both genders are found to be younger and less experienced in private schools. In terms of teaching experience, teachers in public schools have

\footnotetext{
${ }^{4}$ For more details, see Young Lives Technical Note No. 25

${ }^{5}$ Teachers' salary presented in table 1 has been scaled to thousand for estimation purpose.
} 
on average three years' more experience than those in private schools. This is primarily because, teachers in low-fee private schools are usually on short-term contracts and are underpaid, leading to large-scale attrition. This is not the case in public schools, where a large majority of teachers are permanently employed (other than the Vidya Volunteers, who are contractual), and do not wish to give up a permanent public job, which provides them with job security. On examining the teaching qualifications of mathematics teachers, we find that 28 percent of public school teachers hold professional teaching qualifications such as Diploma in Education (DEd) and another 55 percent hold B.Ed/M.Ed degrees, whereas in private school only 8 percent teachers have DEd and 48 percent have B.Ed /M.Ed qualifications. In short, 83 percent of teachers in public schools have acquired professional teaching qualifications compared to 56 percent in private schools. .

Hill et al. (2005) established that teachers' mathematical knowledge for teaching, positively predicted student achievements in mathematics in both first and third grades. Therefore we measure mathematics teachers' content knowledge through a specially designed tool to test teachers' understanding of mathematical concepts and procedures, comprising tasks that assess the teachers' ability to respond to student's errors in mathematics. The data reveal that the average score obtained from the test is significantly (at 1 per cent level of significance) higher for public school teachers than for private school teachers. Thus teachers in public schools display higher content knowledge in mathematics, which may be connected with their higher levels of professional training

It can be argued that in India, if a teacher resides close to their school, or in the same village, this will influence the quality of their teaching positively. Conversely, teachers, who have to travel a long distance to school every day, are likely to come late and this may hinder the quality of their teaching. Time spent on teaching and learning has been shown to have the most consistently positive effect learning of all relevant factors (Walberg 1998) Long-distance travel, may be one of the factors affecting student learning outcomes, as it leads to the late arrival of teachers in a large number of public schools, which often caused by poor local transport facilities. At the same time it is important to recognise that there may exist lack of qualified persons in smaller habitations and in rural areas and teachers from neighbouring habitations or nearby urban areas may be better qualified. 84 percent of the private school teachers were found to be living in the same locality (same village or same mandal/sub-district) where the school was located. Whereas thirty per cent of the public school teachers travelled from a village or town in the same district but outside the mandal or sub-district, i.e. they have to travel long distances to school, as against 15 per cent of teachers in private schools who had to do the same. This may well explain the high rate of absence of public school teachers. This is corroborated by studies such as the School Tells Survey which has revealed that on any given day $25 \%$ of regular teachers are absent and another $22 \%$ arrive late in school (Kingdon, Banerji and Chaudhary, 2008). Eighty-five per cent of the education officials interviewed were also of the view that teacher absenteeism was a major issue in public schools and attributed this to reasons such as lack of transport, long-distance travel and involvement in their personal activities. 
It is pertinent to mention the observation of one of the district education officer interviewed who shared that "-it is mainly the teachers of Primary Schools who are absent from work. This is due to insufficient monitoring of Primary Schools. The teachers are irregular because the Primary Schools are located in remote areas and some Primary Schools are far away from tribal areas where transportation is very less... we should increase the monitoring of these schools. In addition, appropriate punishments should be given to teachers who are irregular to the school. Only then, they will work with total dedication'.

Teacher beliefs are inextricably linked to their decision-making and therefore their professional practice (Pajares 1992). What a teacher feels about his/her own school will have an impact on the quality of their teaching, and will consequently affect student's learning outcomes. A positive attitude, enhanced by teachers' belief in the efficacy of their school, has always been observed as a key characteristic of good teaching. on the other hand if teachers carry negative opinions of their schools ( particularly if this is based on the type of student enrolled in schools), this can well lead to the well-known phenomenon of 'Pygmalion in the Classroom', a selffulfilling prophecy in which students who are thought to be poor learners turn out not to learn well. Eighty-four per cent of private school teachers were found to think that their schools were 'better than other schools in the mandal' while only 54 per cent of teachers felt the same in public schools.

The field surveyors engaged in data collection physically checked the students' books in order to determine how many teachers were regularly providing feedback to students, by marking their books. Although, classroom observations indicated that almost equal numbers of teachers in public and private schools were observed to be setting homework, it is clear from Table 1 that 80 per cent of teachers in private schools were found to have regularly corrected almost every exercise given to students as against only 36 per cent of teachers in public schools. If more than 60 per cent of teachers in public schools are not correcting all the work done by the students, there is obviously a big lacuna that exists in terms of providing students with feedback that they need to enhance learning.

The interpersonal relationship between the teacher and the student is a very important dimension of teaching and learning. The teacher's attitude and disposition toward the students might affect student's learning outcomes. Studies have found similar amounts of variance in examination results explained by interpersonal teacher behaviour to those explained by other teacher behaviours (Goh 1994; Den Brok 2001). Teachers who are perceived as impartial are usually appreciated by students, since it makes them feel that the teacher cares about them. To capture the disposition and attitude of the teacher, we have captured students' perceptions of teacher behaviour through their responses to a teacher behaviour statement, such as 'My class teacher treats me fairly'. While 86 per cent of students in private schools agreed with this statement, implying that the teacher was unbiased and treated them fairly, we find that 77 per cent of Public school students felt the same about their teachers. Differential treatment by the teacher is known to have a significant impact on students' learning outcomes and biased behaviour of teachers is perceived to be greater by students in public school. 
In our sample, students who attend private school belong to households with comparatively higher wealth, more educated parents and more boys in comparison to students attending public schools. Private schools are more likely to be located in urban areas and 86 percent of them offer English medium. On the other hand, Public schools are mostly located in rural areas, only 2 percent of them offer English medium of instruction and around 30 percent of classes are multi-grade, due to combining of students belonging to various grades into a single classroom due to shortage of teachers. Only 2 percent of Private schools on the other hand have multigrade classrooms

\subsection{Measuring the impact of teaching quality on students' learning outcome}

In order to determine how teacher characteristics and teaching practices mentioned in the aforementioned section, affect student's learning outcome, a multivariate regression framework is adopted at the child level wherein students' score in mathematics are regressed against various factors that can affect them. Among the teacher-specific factors, we include all the characteristics of teachers that we discussed earlier in our descriptive analysis (Table 1). To control for household and child level factors we include caste and wealth index of the household. In addition to these variables, some child-specific variables are included, which are age, gender, grade in which the child is currently enrolled; language used by the child during the test and parental education level is included. Moreover, we also control for school quality in terms of physical infrastructure and facilities available within the school, by including a school quality index variable ${ }^{6}$. A dummy variable indicating whether the school is located in a rural or urban area and a dummy variable for an English-medium school are also included. We also control for school size, which is determined by the number of students attending the school. Some class-specific characteristics like number of students in the class (class size) and whether the class is grouped with another class (or other classes) i.e. multi-grade classroom have been included in the regression. There is another important dummy variable we include, which captures whether the school is private or public. One can argue that in addition to all these control variables, there can be some child-specific unobserved heterogeneity which could bias the estimated coefficients. For instance, if students who are more intelligent are sent to private schools, then our model will tend to overestimate the coefficient of the private school dummy. In fact, in the presence of such an endogeneity problem, the other estimates may also become biased and inconsistent. To tackle such a problem, we estimate a second model, where we include an additional control variable capturing the mathematics scores of the students from the past. We capture the past mathematics scores of the students from the Round 3 survey, which was conducted in 2009-10, while the dependent variable is from the school survey data, which was collected in 2010-11. Thus, our specification becomes to some extent dynamic in nature. This type of specification is also known in the literature as a 'value-added' specification (Todd and Wolpin 2003, 2007). One can safely assume that these past test scores of the students reflect their ability to perform well in a mathematics test, and to a large extent they control for child-specific unobserved factors that may contaminate our estimation. However, these two

\footnotetext{
${ }^{6}$ School quality index has been generated by principal component analysis on several binary variables indicating whether the school has facilities like: library, electricity, toilet, playground, chair, table, blackboards and drinking water.
} 
regression models do not control for the bias that may arise due to mandal or sub-district-level unobserved heterogeneity, which may be correlated with both our dependent variable and some of the independent variables. In order to control for these mandal-level fixed effects, we include mandal or sentinel site dummies in the value-added specifications. In an additional regression, we measure the heterogeneous effects of the maths teacher and teaching quality variables in private and public schools. The teacher and teaching quality variables interact with the private school dummy to estimate the heterogeneous effects. We present results from these four specifications in column 1, 2, 3 and 4 respectively in Table 2.

The first column gives the results where the past test score is not included. We see that controlling for other factors, the average score of students going to private schools is significantly higher than those who go to public schools, and the difference is 13 percentage points. The number of years of experience by the teacher and teacher gender do not have any significant impact on student's performance. But the effect of teacher's professional training (D.Ed and B.Ed/M.Ed) is positive and highly significant. Having a teacher with D.Ed raises the test score by 7. 4 percentage points and teacher with B.Ed/M.Ed raises the score by 6 percentage points than having a teacher with only Secondary/Senior secondary pass. We do not find any significant difference between students taught by teachers with Secondary/Senior secondary qualification and students taught by teachers with Bachelor's or Master's degree. Also comparison between professional qualification (D.Ed/B.Ed/M.Ed) and general higher education (B.A/M.A) showed no significant difference in terms of students' outcome.

Teachers' test scores have a positive impact on students' test scores but it is not statistically significant. We find that proximity of teacher's residence from school has a positive effect on student's mathematics score. Teachers who live in the same village or a village or town in the same mandal increase student's mathematics score by 7 percentage points, than teachers who come from a village or town in the same district but outside the mandal. Students for whom every exercise/piece of homework has been checked by the teacher have significantly higher score (6.1 percentage points) than those whose homework has not been checked properly or who do not have any homework book. Teachers who are considered to be fair by the children also resulted in almost 7 percent higher student scores. Teacher salary and teacher attitude are also found to have significant positive impact on student's score. In addition to the linear term for teacher salary, we have also included the quadratic term to capture any nonlinear effect that it may have on students' performance. It is found that the linear term of teacher salary is positive (significant) and the squared term is negative (almost significant). This implies an upward rising concave relationship between teacher salary and students test score. The average marginal effect of a one thousand rupees increase in salary is 0.43 on child's test score. This marginal effect implies that if a teacher is moved upwards from the $25^{\text {th }}$ percentile value (Rs. 2,500 ) to the $75^{\text {th }}$ percentile value (Rs. 15,000 ) in the sample salary distribution, it would raise students test score by 5.6 percentage points. Teacher absenteeism, as captured by student's reports, significantly lowers student's score by 4 percentage points.

Column 2 presents the results of our second model (value-added specification), which has an additional control for past test score. The result from this improved model shows that the control for relevant child-level unobserved factors through the lagged score, is positively 
correlated with the current test score and is highly significant. Comparing the results from these two models we observe that the directions of impacts remain the same, and most of the variables which were significant earlier are found to be significant in this model too. However, we observe that though the coefficient of teacher absenteeism is negative, it is not significant in this specification. The coefficient of the private school dummy has become smaller in magnitude (from 13 in column 1 to 9 in column 2) but it is still significant at 1 per cent level of significance. We also find that teacher's perception of their schools has become significant in this specification. Teacher's positive opinion of their schools ('better than other school') raises the scores by 11 percentage points than those who think their schools are 'worse than other school'. But no significant difference in terms of students' performance has been found between the teachers who think that their schools are 'same as other schools' and those who think that their schools are 'better than other school' in the community. The squared term for teacher salary has become significant at 10 percent level in this specification though the overall effect remains similar.

On controlling for mandal or sub-district level unobserved heterogeneity by incorporating subdistrict level fixed effects (dummies) in the value-added regression in column 3 of the same table, the private school effect remains almost the same (10.2 percentage points). Teaching qualifications (D.Ed and B.Ed/M.Ed) become marginally significant in this specification at 10 percent level of significance. Teacher's place of residence, regular checking of homework by the teachers (every exercise/piece dummy), salary and teachers' attitude towards students and school still have significant effects on student's mathematics score, after controlling for previous achievement score as well as mandal-level heterogeneity.

In the next specification, the private school dummy has been interacted with the teacher and teaching quality specific variables which are significant in earlier specification, to allow for heterogeneity in the effect size of these variables. We see that there are no such teacher characteristics or practices in which significant differences exist across public and private schools. Only exception is D.Ed dummy, for which the interaction with private dummy becomes negative and marginally significant implying that it has lower effect in private school relative to public school. We also find that the coefficient of salary in this specification becomes insignificant referring that the salary has no effect in public school once the differential effects between private and public school is controlled. An estimation of average effect of salary in private schools reveals that on an average an thousand rupee increase in salary is associated with 1.5 percentage point increase in score in private school. This could be because private school teachers are less paid, so an increase in salary encourages them to teach better (refer Table 1 for teacher salary in both the school). This is consistent with the observed non-linear relationship between teacher salary and students outcome, which suggests that the marginal effects are higher at lower levels of teacher salary.

Among the other factors which we used as control variables, present grade in which the student is enrolled, household wealth, mother's education and father's education are seen to have a positive and significant effect on students' learning outcome. The urban sample has a lower average test score than the rural sample. However, mother's education and father's education become insignificant in the value-added specifications after controlling for the previous test 
score and wealth index. Furthermore, the urban dummy become insignificant once we control for the sub-district level unobserved heterogeneity. Students who used Telugu during the test perform better than those who used Urdu or Oriya. However, there is no significant difference between the students who used Telugu and those who used English in answering the Mathematics test.

Thus, our multivariate regression analysis suggests that teachers have a direct effect on variations in test score across both public and private schools. Characteristics like D.Ed and B.Ed/M.Ed training, living in the same village or mandal, checking home-work book and positive attitude towards school and students are important for both types of schools at primary level. However, salary is an important factor only in private school.

\section{Discussion \& Recommendations}

As India is poised to meet the MDG Goals of Universalisation of Primary education, one of the key aspects of guaranteeing quality education will hinge on ensuring that teachers are able to teach effectively and address each student's learning needs. Our multivariate regression analysis suggests that, in terms of the effect on mathematics test score, students in private school perform significantly better than those in public schools, even after controlling for all other factors including the past test score. This corresponds to earlier studies conducted in Andhra Pradesh and elsewhere in the country (Govinda \& Varghese, 1993, Bashir, 199, Kingdon, 2006, Tooley et al2010, Muralidharan \& Kremer, 2006). The analysis shows that the effect of being in a private school vis-a-vis public school results in 10.2 percentage point higher score in mathematics controlling lagged score and sub-district level heterogeneity (Col. 3 in Table 2). The teacher characteristics which emerge as significant determinants of student's learning outcome are teaching credentials such as BEd, MEd and DEd qualifications, their place of living, classroom practices such as checking of books and non-biased treatment of students, their attitude towards schools and regularity as experienced by students. This paper has highlighted some teacher characteristics across public and low fee charging private schools, which have so far not been stressed in earlier studies and draws attention to policy implications of these empirical findings. A refined understanding of how teacher attributes affect their performance across these different teaching contexts can be helpful in determining the range of potentially effective policy options.

\subsection{Teacher Qualification and Redeployment}

An important finding of the analysis is that teachers with D.Ed/B.Ed/M.Ed were found to have significantly higher student outcomes than teachers with only Secondary/Senior secondary qualification.

A public education official interviewed during the Young Lives school survey in a tribal belt remarked '...in this place, there are few qualified teachers (minimum of bachelor of education) and very large proportion are with $10^{\text {th }}$ class education and many of such teachers are not even aware of the importance of education. Qualified teachers alone should be recruited". 
Very significant for policy makers in light of implementation of Right to Education Act, 2010 is the fact that the analysis did not find any significant difference in the effectiveness of teachers with professional teaching qualifications ( D.Ed/B.Ed /M.Ed) and teachers with only general education qualifications such as graduation (BA) or masters (MA). This raises questions regarding the quality of pre-service training imparted in teacher education institutions, particularly in light of the recently introduced Teacher Eligibility Test (TET) for recruitment into government schools in India, in which less than 10 percent professionally qualified teachers passed.

The finding that students had better scores if the teachers were from the same community has implications for teacher recruitment and redeployment. Mpokosa \& Ndaruhutse (2008) highlighted that efficient and effective systems of management, deployment and training (including continuing professional development) are thus critical to achieving the EFA agenda and the MDG's. As RtE is being implemented across states such as Andhra Pradesh, it is critical for teacher rationalization to take place by relocating teachers to both meet the PTR norm as well as be posted in schools closer to their homes. Teachers should ideally belong to the local community, so that we can ensure that teacher absenteeism is controlled to a large extent and time spent in travelling long distances can be utilized fruitfully to support learning of all students.

One of the parents shared "I observed that the teachers in public schools were coming very late and most of the time not taking classes....they do not bother even if a child is absent for number of days.....in private school where my two children are studying (now), teachers are on time and if any child is absent (even) for a day they will enquire with parents.....such concern is important for us"

Since availability of $\mathrm{DEd} / \mathrm{BEd} / \mathrm{MEd}$ qualified teachers is unlikely in smaller, remote habitations, recruitment of motivated graduates in remote rural schools, who are provided onthe-job training, may be an option to consider towards creating an effective cadre for teachers, since they will belong to the local communities and be less likely to be absent. Rather than only focussing on professional qualification tag of teachers, it is critical that policy makers shift their focus to ongoing in-service training and professional development. Also the current preservice teacher training seems to need remodelling and the development of professional standards for teacher training institutes seems necessary in order to ensure that teachers are given the requisite pedagogical content knowledge and skills required to become effective teachers.

\subsection{Teaching Practices}

Since the analysis captures the fact that those students whose books had been checked by the teacher had significantly higher scores, it is useful to analyze this further. Descriptive analysis suggests that 80 percent of the students in Private schools had every exercise or homework checked by their teacher as opposed to 36 percent in public school. The latter may well be related to teacher absenteeism. There is no doubt that teachers behaviours and classroom practices have an impact on students learning levels (Smith, 1979). Though teachers in private schools are paid considerably less than teachers in public schools, a majority of them regularly checked the homework of students and this needs to be given attention within public schools 
as well. Supervision of public schools remains an area of concern, since no robust system of monitoring and mentoring exists.

Kavya Sri's mother is Scheduled Tribe with four daughters, and she did not have the opportunity to attend school. She complains about the public village school where her daughters are enrolled 'One teacher comes, he stay's for an hour, then he says he has to apply for something and he goes off ...he (teacher) comes and sign(attendance register) and when the bus comes, he leaves ...He will appoint one older student to take care of the students. They (students) go to school but they don't know to read or write even a word, we see their slates they don't write anything at all. 'Pointing out the difference between public and private schools she adds 'We can see the education and tell the difference.... For private schools, we pay money, we can question them if students come home early or if they don't study well... if they (teachers) don't teach properly, we won't send the students to their school ...but in Public (schools) the teachers come and teach for the sake of their salaries, they just come and go daily.'

\subsection{Teacher Belief}

Koehler and Grouws (1992) proposed that teacher behaviour is influenced by the teacher's knowledge (of the content to be taught, how learner's learn/understand that specific content and methods to teach that specific content) in addition to teacher's attitude and beliefs about teaching and mathematics. The fact that majority of public schools teachers did not think highly of their schools is an indicator of demotivation that exists amongst teachers and a symptom of the prevailing climate in a large number of public schools. Bennell and Akyeampong (2007) have indicated that teacher management at school level is crucial for teacher motivation and morale. Much of this is related to lack of mentoring of teachers and poor school governance of public schools, already mentioned in the section above. A Mandal Education Officer (MEO) corroborated this by sharing difficulties faced by school supervisors. He shared that "majority MEOs are in-charge MEOs (i.e. are given additional duties and do other jobs as well) and under each MEO there are about 150 head masters and schools... due to this, MEOs are unable to do their work properly. Therefore, to solve this problem we should allocate only 30 schools for each MEO to improve quality".

\subsection{Quality Education- Unrealised}

Teachers in public schools have better teaching qualification as well as subject knowledge, but this has not translated into better student outcomes for a variety of reasons highlighted above. It is useful to reiterate that quality of teaching depends not only on content knowledge, but also on pedagogical knowledge. Pedagogical knowledge is a combination of instructional and content knowledge, knowledge about student's learning styles and current understanding, and understanding about curriculum adaptation and differentiation. This has not been captured sufficiently in this study and requires further analysis of student engagement and classroom teaching learning processes in future. Private schools undoubtedly seem to be relatively better 
than public schools but qualitative interviews also highlight that families may in many cases, not be fully satisfied with private schools.

One mother in an urban site shares:

"I am not satisfied with private school... When we go to join (admit) our child, they promise(d) all the facilities but in reality, there is nothing there..... We are spending a lot of money on these children and there is no change in their behaviour."

Also it seems that parents are forced to compromise and accept whatever quality of schooling is on offer as a mother explains:

'Presently, there is not a single school around that has all the mandatory qualities. We have to overlook certain shortcomings.. Even this (private) school is somewhat better than others are but not the best with all 100\% qualities... we have to compromise and we have to be content with whatever is available. For example, they have to conduct parent teacher meeting at least once in 2 to 3 month but here they did not hold it. In this way there are many issues, which they have not done, but we have to overlook such flaws'

\section{Conclusion}

The question is why are teachers in public schools who are better trained, better qualified, equipped with better content knowledge, and better paid than private school teachers, not leading to better learning outcomes for students? The quality of a school and the quality of teaching of the individual teacher is higher in schools that are able (and willing) to make more efficient use of the available time of its teachers and its pupils (Verwimp, 1999). As pointed out by the qualitative findings, parents are dissatisfied with the fact that teachers in public schools are not paying due attention to teaching their wards and in many instances students leave the school premises during school hours. The existence of this clearly shows that there is a need for greater accountability of public school teachers to ensure students are learning. Though there is about 10 percentage point difference in Mathematics scores between private and public school students and private school may be considered comparatively better than the public school, one should not fail to recognise that public schools continue to remain the only option for children from socially and economically disadvantaged backgrounds, particularly girls. Undoubtedly, public schools are not measuring up to the expectations of serving learning needs of these families, specifically with regard to teaching quality and governance. It is time that benchmarks and standards are developed and initiated for quality assurance across both public and private schools. Furthermore, since the most disadvantaged students continue to enrol in public schools- it is critical that they are not 'short changed'. This is critically important in light of the huge investment, being made by state and central government to support public schools. 
Our paper highlights that it is what the teacher 'believes and does' in the classroom that has maximum impact on student's outcomes. Teachers' beliefs and attitudes will need to be given critical importance in teacher development programmes. All these factors are of equal importance in both types of schools. There exists an urgency to introduce a reform process in the teacher education as well as the planning and monitoring systems that exist within the education system, with a focus on teaching quality. Quality standards for teacher professional development and curriculum re-formulation to ensure quality preparation of teachers with skills required to serve the most marginalized students, must become a policy imperative. Furthermore, robust appraisal systems linked to teacher performance for public schools and teacher mentoring needs to be given immediate attention.

Parents have huge aspirations and are making tremendous sacrifices in order to enable their wards to have a better life than their own. It is not only an imperative but a compulsion that, the education system reforms itself to meet these demands, by investing and preparing an effective teaching force and monitoring mechanism, to realise their dreams.

Supraja's mother echoes the aspirations of millions of poor parents:

'People are not worried about their economic background or financial position .... they are only bothered about their children's education. They are prepared to give up anything for the sake of their children's education. They want to give their children whatever they missed in their childhood and they want their students to attain that position which they failed to get' 


\section{References:}

ASER (2010) Sixth Annual Status of Education Report, New Delhi: Pratham Foundation, http://www.pratham.org/aser-report (accessed 2 June 2011)

ASER(2011) Seventh Annual Status of Education Report (Rural), New Delhi: Pratham Foundation, http://img.asercentre.org/docs/Publications/ASER\%20Reports/ASER_2011/aser_2011_report 8.2.12.pdf (accessed June 2012)

Barber, M. and M. Mourshed (2007) How the World's Best-performing School Systems Come out on Top, London: McKinsey and Company.

Bashir, S. (1997) 'The Cost-effectiveness of Public and Private Schools: Knowledge Gaps, New Research Methodologies and an Application in India' in C. Colclough (ed.) Marketizing Education and Health in Developing Countries: Miracle or Mirage?, Oxford: Clarendon Press

Bennell, P. and Akyeampong, K. (2007)Teacher Motivation in Sub-Saharan Africa and South Asia, DFID Educational Paper No. 71. DFID, London

Darling-Hammond, L. (2000) 'Teacher Quality and Student Achievement: A Review of State Policy Evidence', Education Policy Analysis Archives 8.1: http://epaa.asu.edu/ojs/article/view/392/515 (accessed on 10 April 2010).

De, A., C. Noronha and M. Samson (2001) India: Private Schools and Universal Elementary Education, South Asia Education Sector, Technical Working Paper No. 3, Washington DC: World Bank.

Den Brok, P. (2001) Teaching and Student Outcomes: A study on Teachers' Thoughts and Actions from an Interpersonal and a Learning Activities Perspective, Utrecht: Institute of Education, University of Utrecht.

DISE (2010-11) Elementary Education In India, Flash Statistics, New Delhi: National University of Educational Planning and Administration

Fenstermacher, G.D. and V. Richardson (2005) 'On Making Determinations of Quality in Teaching', Teachers College Record 107.1: 186-213.

Fuller, B. and P. Clarke (1994) 'Raising School Effects While Ignoring Culture? Local Conditions and the Influence of Classroom Tools, Rules and Pedagogy', Review of Educational Research 64.1: 119-57. 
Galab, S., V. Kumar, P. Reddy, R Singh and U. Vennam (2011) The Impact of Growth on Childhood Poverty in Andhra Pradesh, Round 3 Survey Report, Oxford: Young Lives

Goh, S.C. (1994) 'Interpersonal Teacher Behavior, Classroom Climate and Student

Outcomes in Primary Mathematics Classes in Singapore', unpublished doctoral thesis, Curtin University of Technology, Perth, Australia:

Govinda, R. and N. Varghese (1993) Quality of Primary Schooling in India: A Case Study of Madhya Pradesh, International Institute for Educational Planning, National Institute of Educational Planning and Administration.

Hill, H.C., B. Rowan and D.L. Ball (2005) 'Effects of Teachers' Mathematical Knowledge for Teaching on Student Achievement' American Educational Research Journal 42.2: 371406

Kingdon, G. (1996a) 'Private Schooling in India: Size, Nature and Equity Effects', Economic and Political Weekly 31.51: 3306-14

Kingdon, G. (1996b) 'The Quality and Efficiency of Public and Private Schools: A Case Study of Urban India', Oxford Bulletin of Economics and Statistics 58.1: 55-80

Kingdon, G. (2006) Teacher Characteristics and Student Performance in India: A pupil fixed-effects approach, GPRG-WPS-059, Oxford: Global Poverty Research Group, Department of Economics, University of Oxford

Kingdon, G., R. Banerji and P. Chaudhary (2008) 'SchoolTELLS Survey of Rural Primary Schools in Bihar and Uttar Pradesh, 2007-08', Unpublished survey, London: Institute of Education

Koehler, M.S. and D.A. Grouws (1992) 'Mathematics Teaching Practices and Their Effects' in D.A. Grouws(ed.) Handbook of Research on Mathematics Teaching and Learning: A Project of the National Council of Teachers of Mathematics, New York, NY: Macmillan

Majumdar, M. (2001) 'Educational Opportunities in Rajasthan and Tamil Nadu: Despair and Hope' in A. Vaidyanathan and P.R. Gopinathan Nair (eds) Elementary Education in Rural India-A Grassroots View, New Delhi: Sage Publications.

Mpokosa, C \& Ndaruhutse, S (2008) Managing Teachers: The centrality of teacher management to quality education. Lessons from developing countries, VSO-CfBT Publlication

Muralidharan, K. and M. Kremer (2006) 'Public and Private Schools in Rural India', in P. Peterson and R. Chakrabarti (eds) School Choice International, Cambridge, MA: MIT Press. Pajares, M. (1992). 'Teachers' Beliefs and Educational Research: Cleaning up a Messy Construct', Review of Educational Research 6: 307-32

PROBE (1999) Public Report on Basic Education in India, Delhi: Oxford University Press. 
Ramachandran, V. and A. Saihjee (2002) 'The New Segregation: Reflections on Gender and Equity in Primary Education', Economic and Political Weekly 37.17: 1600-13.

Rivkin, S.G., E.A. Hanushek and J.F. Kain (2005) 'Teachers, Schools, and Academic Achievement', Econometrica 73.2: 417-58.

Rockoff, J.E. (2004) 'The Impact of Individual Teachers on Student Achievement: Evidence from Panel Data', American Economic Review 94.2: 247-52.

Singh, R and Sarkar. S (2012) Teaching Quality Counts: How Student Outcomes relate to Quality of Teaching In Private and Public Schools in India, Young Lives Working Paper 91

Smith , H. A. (1979). Nonverbal communication in teaching. Review of Educational Research, 49, 631-672.

Todd, P. and K. Wolpin (2007) 'The Production of Cognitive Achievement in Students: Home, School, and Racial Test Score Gaps', Journal of Human Capital 1.1: 91-36

Todd, P. and K. Wolpin (2003) 'On the Specification and Estimation of the Production Function for Cognitive Achievement', The Economic Journal 113.485: F3-F33

Tooley, J. and P. Dixon (2003) Private Schools for the Poor: A Case Study from India, Reading: CfBT Research and Development

Tooley, J., P. Dixon and S.V. Gomathi (2007) 'Private Schools and the Millennium Development Goal of Universal Primary Education: A Census and Comparative Survey inHyderabad, India', Oxford, Review of Education 33.5: 539-60.

Tooley, J., Dixon, P., Shamsan, Y., \& Schagen, I. (2010) The relative quality and costeffectiveness of private and public schools for low-income families: a case study in a developing country, School Effectiveness and School Improvement: An International Journal of Research, Policy and Practice, 21:2, 117-144

Verwimp, P. (1999) 'Measuring the Quality of Education at Two Levels: A Case Study of Primary Schools in Rural Ethiopia', International Review of Education 45.2: 167-96.

Walberg, H.J. (1998) 'Uncompetitive American Schools: Causes and Cures' in D. Ravitch (ed.), Brookings Papers on Education Policy, Washington, DC: Brookings Institution

Woodhead, M., M. Frost and Z. James (2011) 'Does Growth in Private Schooling Contribute to Education For All? Evidence from a Longitudinal Two-Cohort study in Andhra Pradesh, India', draft prepared for International Journal of Educational Development

Wyatt, T. (1996) 'School Effectiveness Research: Dead End, Damp Squib or Smouldering Fuse?' Issues in Educational Research 6.1: 79-112 